\title{
The practical clinical value of three-dimensional models of complex congenitally malformed hearts
}

\author{
Eugénie Riesenkampff, MD, ${ }^{\mathrm{a}, *}$ Urte Rietdorf, MSc, ${ }^{\mathrm{b}, *}$ Ivo Wolf, $\mathrm{PhD},{ }^{\mathrm{b}}$ Bernhard Schnackenburg, $\mathrm{PhD},{ }^{\mathrm{c}}$ \\ Peter Ewert, MD, ${ }^{\mathrm{a}}$ Michael Huebler, MD, ${ }^{\mathrm{d}}$ Vladimir Alexi-Meskishvili, MD, ${ }^{\mathrm{d}}$ Robert H. Anderson, MD, \\ Nicole Engel, MD, ${ }^{\mathrm{b}}$ Hans-Peter Meinzer, PhD, ${ }^{\mathrm{b}}$ Roland Hetzer, MD, ${ }^{\mathrm{d}}$ Felix Berger, MD, ${ }^{\mathrm{a}}$ \\ and Titus Kuehne, MD
}

Objective: Detailed 3-dimensional anatomic information is essential when planning strategies of surgical treatment for patients with complex congenitally malformed hearts. Current imaging techniques, however, do not always provide all the necessary anatomic information in a user-friendly fashion. We sought to assess the practical clinical value of realistic 3-dimensional models of complex congenitally malformed hearts.

Methods: In 11 patients, aged from 0.8 to 27 years, all with complex congenitally malformed hearts, an unequiv-
ocal decision regarding the optimum surgical strategy had not been reached when using standard diagnostic tools.
Therefore, we constructed 3-dimensional virtual computer and printed cast models of the heart on the basis of
high-resolution whole-heart or cine magnetic resonance imaging or computed tomography. Anatomic descrip-
tions were compared with intraoperative findings when surgery was performed.

Results: Independently of age-related factors, images acquired in all patients using magnetic resonance imaging and computed tomography proved to be of sufficient quality for producing the models without major differences in the postprocessing and revealing the anatomy in an unequivocal 3-dimensional context. Examination of the models provided invaluable additional information that supported the surgical decision-making. The anatomy as shown in the models was confirmed during surgery. Biventricular corrective surgery was achieved in 5 patients, palliative surgery was achieved in 3 patients, and lack of suitable surgical options was confirmed in the remaining 3 patients.

Conclusion: Realistic 3-dimensional modeling of the heart provides a new means for the assessment of complex intracardiac anatomy. We expect this method to change current diagnostic approaches and facilitate preoperative planning.

Over the past decades, continuous refinement of imaging, surgical, interventional, and anesthetic techniques have produced steadily decreasing rates of mortality for patients with congenitally malformed hearts. A precise preoperative assessment of anatomy, along with the prevailing hemodynamic conditions, can be challenging in the setting of

\footnotetext{
From the Deutsches Herzzentrum Berlin, Unit of Cardiovascular Imaging, Department of Congenital Heart Disease and Pediatric Cardiology, ${ }^{\mathrm{a}}$ Berlin, Germany; German Cancer Research Centre Heidelberg, Division of Medical and Biological Informatics, ${ }^{\text {b }}$ Heidelberg, Germany; Philips Medical Systems, ${ }^{c}$ Hamburg, Germany; Deutsches Herzzentrum Berlin, Department of Cardiothoracic and Vascular Surgery, ${ }^{\mathrm{d}}$ Berlin, Germany; and University College London, Cardiac Unit, Institute of Child Health, ${ }^{\mathrm{e}}$ London, United Kingdom.

*E.R. and U.R. contributed equally to this article.

This work was supported by the German Science Association (DFG) and the German Federal Ministry of Education and Research, grant KU1329/5-1 and 01EV0704, and by the "Fördergemeinschaft deutscher Kinderherzzentren." Responsibility for the contents rests with the authors.

Received for publication Nov 7, 2008; revisions received Jan 14, 2009; accepted for publication March 9, 2009; available ahead of print June 8, 2009.

Address for reprints: Eugénie Riesenkampff, MD, Deutsches Herzzentrum Berlin, Department of Congenital Heart Disease and Pediatric Cardiology, Augustenburger Platz 1, D-13353 Berlin, Germany (E-mail: riesenkampff@dhzb.de).

J Thorac Cardiovasc Surg 2009;138:571-80

$0022-5223 / \$ 36.00$

Copyright (c) 2009 by The American Association for Thoracic Surgery

doi:10.1016/j.jtcvs.2009.03.011
}

complex malformations but is crucial for both decisionmaking and the eventual outcome. Methods available for imaging, including echocardiography, x-ray angiography, computed tomography (CT), and magnetic resonance imaging (MRI), have also shown huge advances in recent years. In conjunction with improved postprocessing modalities, they now provide images of ever increasing quality. These different modalities are often used in combination, because each has its distinctive advantages and disadvantages. The ideal end point, still difficult to achieve, is to provide a comprehensive 3-dimensional (3D) visualization of the entire intracardiac anatomy, thus providing clear information about the spatial relationships of the intracardiac and extracardiac structures. Crucial anatomic information as presented with these standard techniques, however, is not always currently interpreted in uniform fashion by all observers. This is more so when considering options for surgical treatment. Such lack of consensus can impinge directly on the chosen strategies and thus influence markedly the outcome for the patients.

It is now recognized that computerized models of human anatomy prepared in 3 dimensions can provide detailed spatial information. Such physical models, made by rapid 


\section{Abbreviations and Acronyms \\ $\mathrm{CT}=$ computed tomography \\ MRI $=$ magnetic resonance imaging \\ $3 \mathrm{D}=3$ dimensional}

prototyping techniques, were first used in oral and maxillofacial surgery, neurosurgery, and orthopedics. ${ }^{1,2}$ With the evolvement of technologies for imaging, it has become feasible to generate 3D models of congenitally malformed hearts from living patients. ${ }^{3}$ Several pilot reports have now described the use of such models for the visualization of cardiovascular anatomy. These reports, however, have thus far represented only cases of extracardiac or single anecdotal accounts of intracardiac anatomy. ${ }^{4-11}$ One recent study, nonetheless, showed the feasibility of creating accurate 3D virtual models of the heart using MRI data from a larger group of patients with different kinds of congenitally mal- formed hearts. ${ }^{12}$ We present our own initial experience in creating computerized 3D models of complex congenitally malformed hearts, stressing the practical clinical value of this approach.

\section{MATERIALS AND METHODS}

We studied a total of 11 patients, aged from 0.8 to 27 years, all with complex congenitally malformed hearts. Before inclusion, the patients had undergone investigation using routine diagnostic tools, including echocardiography, diagnostic catheterization, MRI, and optional CT. These routine images were presented in our surgical conference, which was attended by 2 cardiac surgeons, with extensive experience in the field of the congenitally malformed heart, and 4 pediatric cardiologists. After these discussions, questions remained about certain anatomic relationships, particularly about the best option for surgical treatment (Table 1). The questions devolved largely on the choice between biventricular corrective as opposed to functionally univentricular or palliative surgery. In 1 patient, the problem centered on the chances of successful closure of a "Swiss-cheese" ventricular septum. In all patients, therefore, we constructed computerized 3D models to facilitate how best the surgery could be performed and to show if it was possible to achieve biventricular
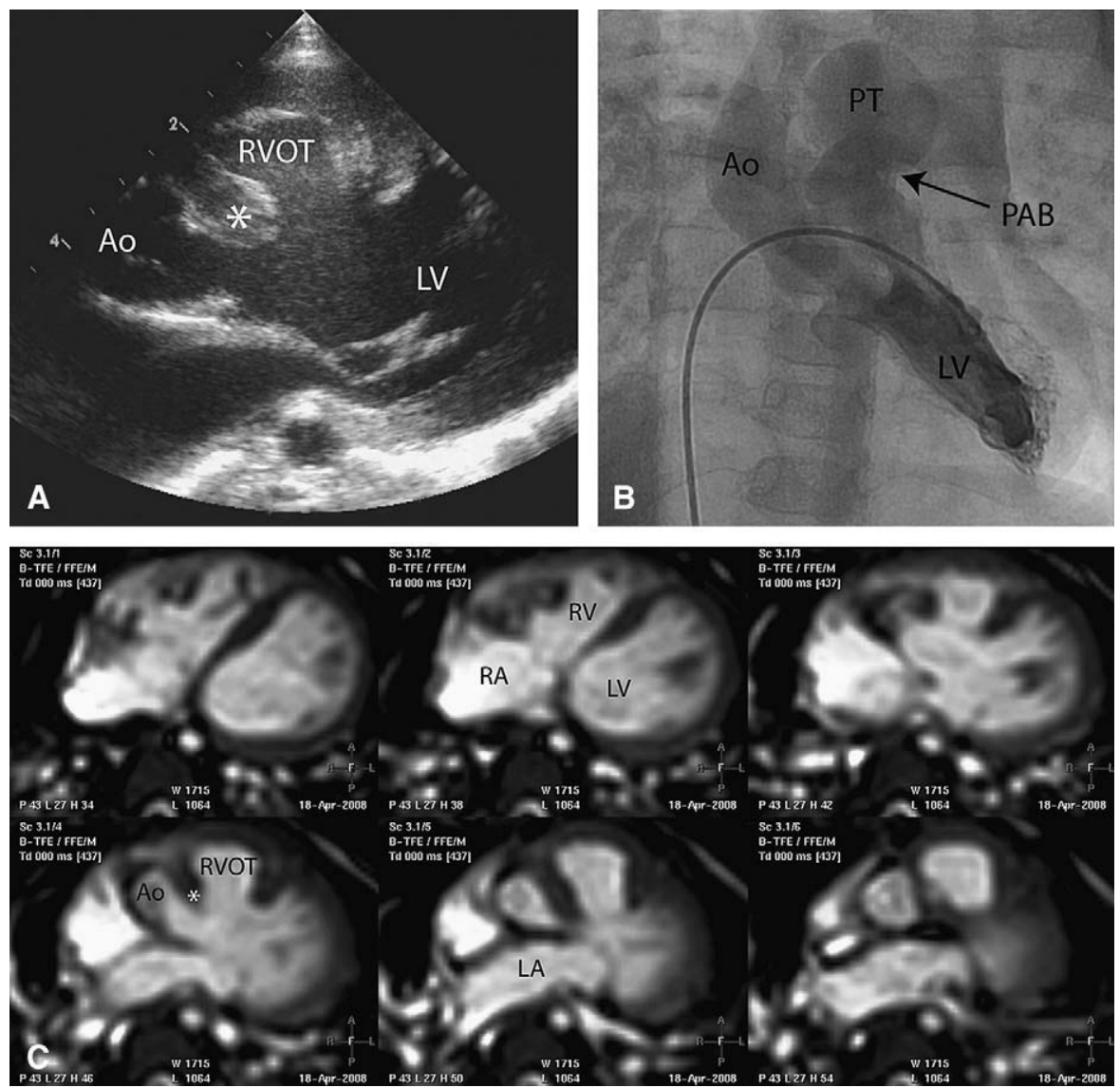

FIGURE 1. Standard diagnostic imaging of patient 1 with double-outlet right ventricle and obstruction of the left ventricular outflow tract. Echocardiography (A), cardiac catheterization (B, anterior view of a left ventricular angiography, with a catheter placed into the left ventricle through the interventricular communication), and standard MRI (C, transversal cine MRI in end diastole). The muscle band (*) obstructing the left ventricular outflow tract. Ao, Ascending aorta; $L A$, left atrium; $L V$, left ventricle; $P A B$, pulmonary arterial band; $P T$, pulmonary trunk; $R A$, right atrium; $R V$, right ventricle; $R V O T$, right ventricular outflow tract. 
TABLE 1. Patient characteristics

\begin{tabular}{|c|c|c|c|c|c|c|c|}
\hline Patient no. & Age (y) & Sex & Diagnosis & $\begin{array}{l}\text { Former operations/ } \\
\text { interventions }\end{array}$ & $\begin{array}{l}\text { Imaging for 3D } \\
\text { model }\end{array}$ & Question & $\begin{array}{c}\text { Surgical } \\
\text { recommendation }\end{array}$ \\
\hline 1 (Figures 1-4) & 1.6 & F & $\begin{array}{l}\text { DORV, LVOTO due } \\
\text { to infundibular } \\
\text { muscle, coarctation } \\
\text { of the aortic isthmus }\end{array}$ & $\begin{array}{l}\text { Pulmonary arterial } \\
\text { band, Correction of } \\
\text { coarctation }\end{array}$ & $\begin{array}{l}\text { 3DWH } \\
\text { Sedation }\end{array}$ & $\begin{array}{l}\text { Morphology of VSD } \\
\text { and relation } \\
\text { to outflow tracts }\end{array}$ & $\begin{array}{l}\text { Biventricular repair } \\
\quad \text { (see text for details) }\end{array}$ \\
\hline 2 (Figures 5 and 6) & 0.9 & $\mathrm{~F}$ & $\begin{array}{l}\text { DORV, multiple } \\
\text { VSDs, valvar PS }\end{array}$ & None & $\begin{array}{c}\text { 3DWH } \\
\text { Sedation }\end{array}$ & $\begin{array}{l}\text { Morphology of VSDs } \\
\text { and relation } \\
\text { to outflow tracts }\end{array}$ & $\begin{array}{l}\text { Biventricular repair } \\
\quad \text { (see text for details) }\end{array}$ \\
\hline 3 (Figures 7 and 8) & 5.0 & M & $\begin{array}{l}\text { Swiss-cheese VSDs, } \\
\text { RVOTO, valvar PS, } \\
\text { residual VSDs }\end{array}$ & $\begin{array}{l}\text { Repeated surgical } \\
\text { and interventional } \\
\text { closure } \\
\text { of VSDs, RVOT, } \\
\text { infundibulectomy } \\
\text { and patch } \\
\text { enlargement }\end{array}$ & $\begin{array}{c}\text { CT } \\
\text { Esmolol } \\
\text { GA }\end{array}$ & $\begin{array}{l}\text { Approach to residual } \\
\text { VSDs }\end{array}$ & $\begin{array}{l}\text { Patch closure } \\
\text { through left } \\
\text { ventriculotomy } \\
\text { (see text for details) }\end{array}$ \\
\hline 4 & 19 & M & $\begin{array}{l}\text { DORV, cAVSD, } \\
\text { multiple } \\
\text { muscular VSDs, } \\
\text { RVOTO, valvar PS }\end{array}$ & $\begin{array}{l}\text { RVOT, } \\
\text { infundibulectomy } \\
\text { and patch } \\
\text { enlargement }\end{array}$ & Cine MRI & $\begin{array}{l}\text { Morphology of VSDs } \\
\text { and relation } \\
\text { to outflow tracts }\end{array}$ & No surgery \\
\hline 5 & 0.8 & $\mathrm{~F}$ & $\begin{array}{l}\text { TOF, severe PS, large } \\
\text { VSD, straddling } \\
\text { of tricuspid valve }\end{array}$ & Infundibulectomy & $\begin{array}{l}\text { 3DWH } \\
\text { Esmolol } \\
\text { Sedation }\end{array}$ & $\begin{array}{l}\text { Morphology of VSD } \\
\text { and relation } \\
\text { to inflow and } \\
\text { outflow tracts }\end{array}$ & Biventricular repair \\
\hline 6 & 19 & M & $\begin{array}{l}\text { ccTGA, pulmonary } \\
\text { atresia, VSD }\end{array}$ & $\begin{array}{l}\text { Repeated AP shunt, } \\
\text { patch enlargement } \\
\text { of pulmonary } \\
\text { artery bifurcation }\end{array}$ & $3 \mathrm{DWH}$ & $\begin{array}{l}\text { Morphology of VSD } \\
\text { and relation } \\
\text { to outflow tracts }\end{array}$ & Biventricular repair \\
\hline 7 & 4.7 & $\mathrm{~F}$ & $\begin{array}{l}\text { DORV, large VSD, } \\
\text { valvar PS, severe } \\
\text { LVOTO }\end{array}$ & $\begin{array}{l}\text { AP shunt, } \\
\text { Glenn procedure } \\
\text { with ligation of } \\
\text { pulmonary trunk }\end{array}$ & $\begin{array}{c}\text { 3DWH } \\
\text { Sedation }\end{array}$ & $\begin{array}{l}\text { Morphology of VSD } \\
\text { and relation } \\
\text { to outflow tracts }\end{array}$ & $\begin{array}{l}\text { Univentricular } \\
\text { palliation (TCPC) }\end{array}$ \\
\hline 8 & 6.5 & M & TGA, valvar PS, VSD & $\begin{array}{l}\text { Repeated AP shunt, } \\
\text { Glenn procedure, } \\
\text { enlargement } \\
\text { of VSD }\end{array}$ & $3 \mathrm{DWH}$ & $\begin{array}{l}\text { Morphology of VSD } \\
\text { and relation } \\
\text { to outflow tracts }\end{array}$ & $\begin{array}{l}\text { Univentricular } \\
\text { palliation (TCPC) }\end{array}$ \\
\hline 9 & 10 & M & $\begin{array}{l}\text { AVSD, unbalanced } \\
\text { ventricles, } \\
\text { subvalvar PS }\end{array}$ & $\begin{array}{l}\text { AP shunt, } \\
\text { Glenn procedure }\end{array}$ & $3 \mathrm{DWH}$ & $\begin{array}{l}\text { Morphology of VSD } \\
\text { and relation } \\
\text { to outflow tracts }\end{array}$ & $\begin{array}{l}\text { Univentricular } \\
\text { palliation (TCPC) }\end{array}$ \\
\hline 10 & 24 & M & $\begin{array}{l}\text { ccTGA, pulmonary } \\
\text { atresia, VSD }\end{array}$ & $\begin{array}{l}\text { Repeated AP shunt, } \\
\text { patch enlargement } \\
\text { of pulmonary } \\
\text { arteries }\end{array}$ & $3 \mathrm{DWH}$ & $\begin{array}{l}\text { Morphology of VSD } \\
\text { and relation } \\
\text { to outflow tracts }\end{array}$ & No surgery \\
\hline 11 & 27 & F & $\begin{array}{l}\text { Multiple muscular } \\
\text { VSDs, TAPVC, } \\
\text { discordant } \\
\text { atrioventricular } \\
\text { connections, } \\
\text { infundibular } \\
\text { and valvar PS }\end{array}$ & None & $3 \mathrm{DWH}$ & Surgical options & No surgery \\
\hline
\end{tabular}

$A S D$, Atrial septal defect; $A V$, atrioventricular; $c c T G A$, congenitally corrected transposition; $D I L V$, double-inlet left ventricle; $D O R V$, double-outlet right ventricle; $G A$, general anesthesia; $L V O T O$, left ventricular outflow tract obstruction; $P S$, pulmonary stenosis; RVOT, right ventricular outflow tract; $R V O T O$, right ventricular outflow tract obstruction; $T A P V C$, totally anomalous pulmonary venous connection; $T C P C$, total cavopulmonary anastomosis; TGA, transposition; TOF, tetralogy of Fallot; $V S D$, ventricular septal defect.

circulations. All models were made from the data already obtained from MRI or CT studies. For judgment of their utility, the models were presented to a subsequent surgical conference, which was attended by the same participants. Anatomic details, as shown in the models, were ulti- mately compared with the intraoperative findings. Approval was obtained from the local research ethics committee, who waived the need for signed consent, because all performed imaging was part of our routine clinical investigation. 

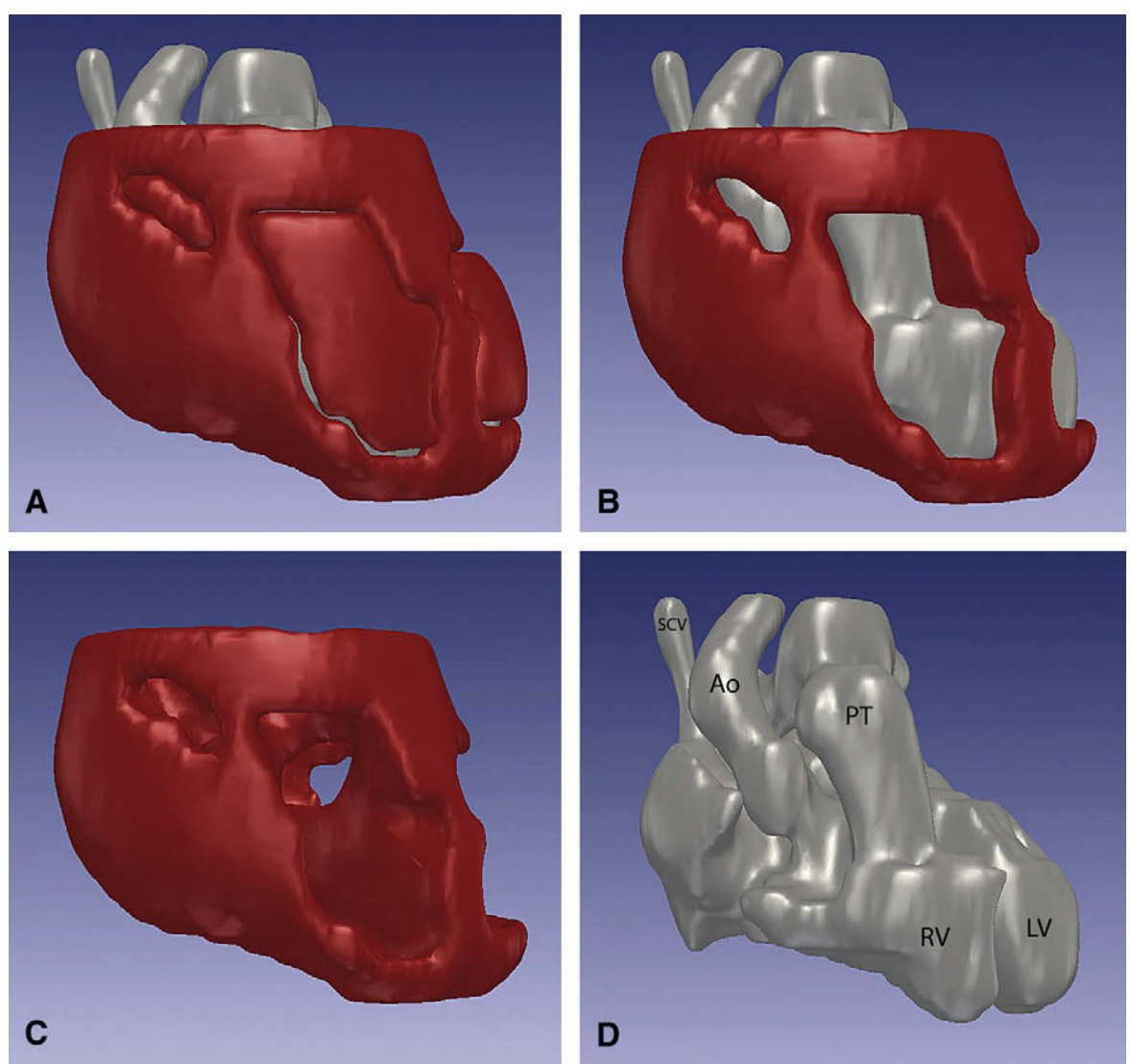

FIGURE 2. Virtual 3D model of patient 1. The model is composed of different elements that can be separated into blood-pool (D) and surface (C) models. In the latter, viewing windows, for visualization of intracardiac structures, can be incorporated in arbitrary position and size (A, B). $A o$, Ascending aorta; $L V$, left ventricle; $P T$, pulmonary trunk; $R V$, right ventricle; $S C V$, superior caval vein.

\section{Imaging}

MRI was performed within a 1.5 Tesla system using the sense-cardiac coil (both from Philips, Best, The Netherlands). The heart models were made from high-resolution, free-breathing, navigator-triggered wholeheart images or from multiphase-multislice cine images covering the whole heart. Both scanning sequences were based on steady-state, freeprecession techniques. Scan parameters for the whole heart images were as follows: echo time $2.4 \mathrm{~ms}$; repetition time $5.1 \mathrm{~ms}$; matrix 181 to $285 \times 432$ to 528 ; field of view 300 to $360 \mathrm{~mm}$; flip angle 90 degrees; measured voxel size $1.2 \times 1.2 \times 1.8 \mathrm{~mm}^{3}$, reconstructed to 0.7 $\times 0.7 \times 0.9 \mathrm{~mm}^{3}$. The acquisition time ranged from 3 minutes and 10 seconds to 7 minutes and 55 seconds. Parameters for cine images were as follows: echo time $1.8 \mathrm{~ms}$; repetition time $3.6 \mathrm{~ms}$; flip angle 60 degrees; matrix $176 \times 256$; field of view $350 \mathrm{~mm}$; slice thickness $6.0 \mathrm{~mm}$; gap $-4.5 \mathrm{~mm} ; 25$ phases per cardiac cycle. The acquisition time was 6 minutes and 20 seconds.

During the initial studies, 6 patients were compliant, whereas for 4 patients (aged $0.8,0.9,1.6$, and 4.7 years), imaging was performed using conscious sedation achieved by intravenous administration of a bolus of midazolam $(0.1-0.2 \mathrm{mg} / \mathrm{kg})$, followed by continuous infusion of propofol $(2-4 \mathrm{mg} / \mathrm{kg} / \mathrm{h})$. In 1 patient, reduction of the heart rate was achieved by intravenously administered esmolol (100 $\mu \mathrm{g} / \mathrm{kg} / \mathrm{min})$.

Electrocardiographically gated computed tomographic scanning, using Siemens Somatom Definition (New York, NY), dual source, 64 slices, was performed in 1 patient under general anesthesia with forced breath-holding in expiration and intravenous administration of esmolol after administra- tion of a bolus of contrast agent (Iomeprol, $81.65 \mathrm{~g} / 100 \mathrm{~mL}$, Bracco, Italy). Scan parameters were as follows: matrix $512 \times 512$, field of view $145 \mathrm{~mm}$, and slice thickness $0.8 \mathrm{~mm}$. The acquisition time was 6 seconds.

\section{Postprocessing}

Data postprocessing was done inside an application using the Medical Imaging and Interaction Toolkit. ${ }^{13}$ To create a heart model, the heart outline and blood volume have to be defined, for which several solutions with different degrees of automation are provided. Currently, a semiautomatic definition with simplex meshes ${ }^{14}$ is used for the heart muscle, and a thresholdbased method is used to define the blood volume. This provides 2 model types: one showing the blood pool and one showing the surface of the heart. The time needed for defining the blood volume was reduced from 2 to 3 hours to approximately 40 minutes because of the gain in experience using the software and optimized data management.

For each patient, virtual computer and physically printed models were constructed, which were presented in the surgical conference. Printing was realized by rapid prototyping techniques using the 3D printer ZPrinter 310 (Z Corporation, Burlington, MA), which creates numerous thin layers of powder based on plaster, using an original inkjet print head to jet a binder down onto the powder. At the end of the building process, the remaining loose powder is vacuumed off to leave the final solid model. Viewing windows, which are user defined in terms of number, size, and position, permit visualization of the anatomic areas of interest within the heart. 

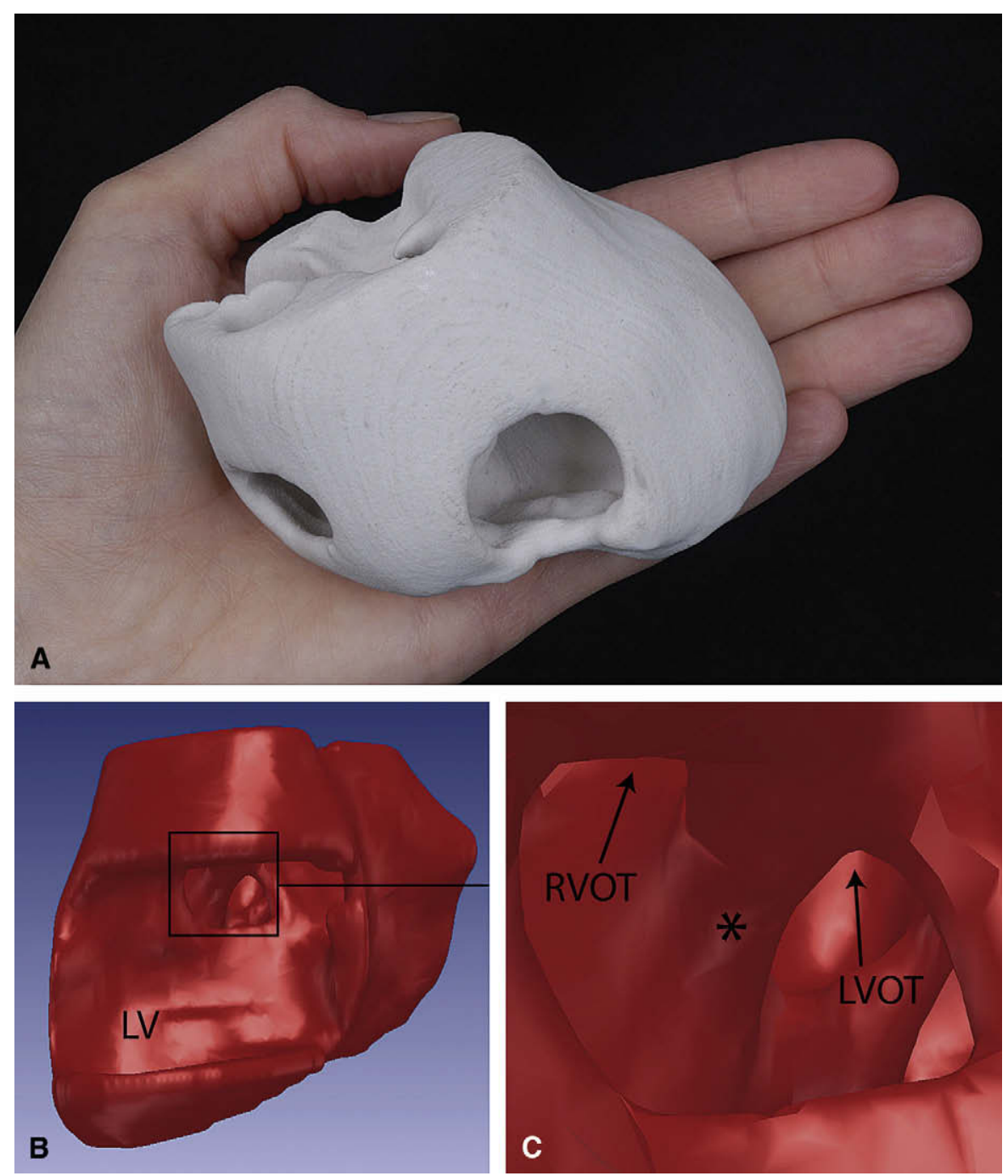

FIGURE 3. Printed and virtual 3D surface model of patient 1 . A, Realistic printed surface model with a small viewing window in the right atrium and right ventricle. B, Model is shown as a virtual version with view into the left ventricle. C, Anatomic details that are crucial for surgical decision making are enlarged, showing the interventricular communication in relation to the right ventricular outflow tracts. The muscle band $(*)$ obstructing the interventricular communication. $L V$, Left ventricle; $L V O T$, left ventricular outflow tract; $R V O T$, right ventricular outflow tract.

\section{RESULTS}

In all patients, it proved possible to construct the computerized models from the images already acquired using MRI or CT independently of age-related factors. There were no major differences between the methods in terms of the postprocessing. Clinical and anatomic data are summarized in Table 1 . The models were judged to be invaluable by those participating in the surgical conference. The anatomy demonstrated by the models agreed well with the intraoperative findings. After the models were studied, biventricular corrective surgery was recommended in 4 patients. In 3 patients, the models suggested that no safe pathways existed to permit biventricular correction, so the functionally univentricular approach was preferred. In another 3 patients, the models suggested that no option existed for surgical correction or palliation. In the patient with the Swiss-cheese ventricular septum, it was recommended that closure be attempted via a left ventriculotomy (see details below).

For 3 representative patients, we present the preoperative imaging data, together with more detailed anatomic and clinical information. To improve visual perception, all imaging material presented is also available to be downloaded in movie format from the website www.dhzb.de/movies/ 3Dmodels.

\section{Patient 1}

A 20-month-old girl with double-outlet right ventricle was investigated for possible biventricular corrective surgery. As a neonate, she had undergone banding of the pulmonary trunk and surgical correction of aortic coarctation. 

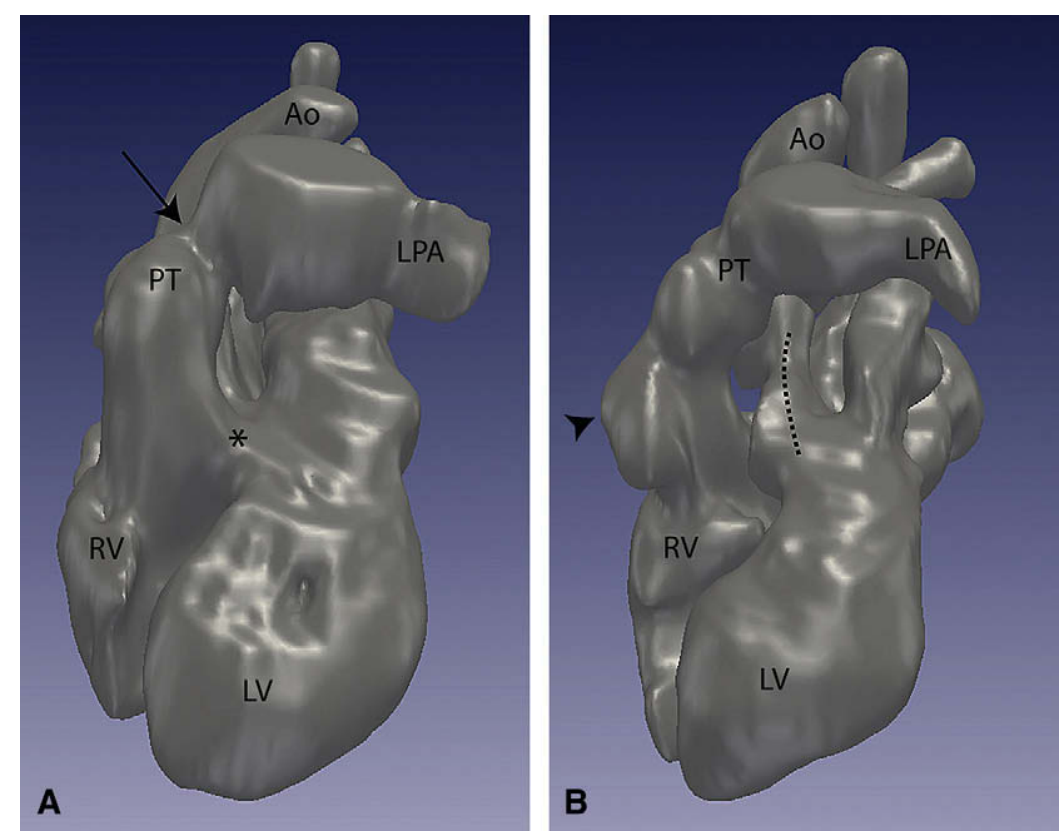

FIGURE 4. Blood-pool model of patient 1 pre- and postoperatively. Left lateral view preoperatively (A) and postoperatively (B). Because of the reconstruction of the outflow from the left ventricle (dotted line, B) through the former interventricular communication $\left(^{*}, \mathrm{~A}\right)$, the right ventricular outflow tract was narrowed and had to be enlarged with a patch (arrowhead, B). The band on the pulmonary trunk (arrow, A) was removed. Ao, Ascending aorta; LPA, left pulmonary artery; $L V$, left ventricle; $P T$, pulmonary trunk; $R V$, right ventricle.

It was known that the outflow from the left ventricle through the interventricular communication was partially obstructed by infundibular musculature. Because she possessed 2 welldeveloped ventricles, the favored surgical strategy was to create a baffle from the left ventricle to the aorta. The precise relationships of the interventricular communication, representing the outflow tract of the left ventricle and the origins of the arterial trunks from the right ventricle, could not be clarified with routine imaging (Figure 1). This anatomic information was clearly provided by the model (Figures 2, 3, and 4, A). On the basis of this information, it proved possible to resect the ventriculo-infundibular fold in the roof of the interventricular communication, tunnel the defect to the aorta, enlarging the outflow tract with a patch, and deband the pulmonary trunk. The excellent postoperative result was further demonstrated in a new model (Figure 4, B).

\section{Patient 2}

An 11-month-old girl presented with double-outlet right ventricle, multiple ventricular septal defects, and valvar pulmonary stenosis. The exact nature of the septal defects and their relationship to the outflow tracts remained unclear after routine imaging (Figure 5). Because of this, it was difficult to judge whether the interventricular communication could be tunneled to one or the other arterial root to achieve biventricular correction. The model revealed the presence of a muscle band dividing the interventricular communication, the inferior part of which was perimembranous, and that space ex- isted to create an unobstructed tunnel from the left ventricle to the aorta (Figure 6). During surgery, the band was resected and the tunnel was created as predicted without obstruction.

\section{Patient 3}

A 5-year-old patient had undergone several surgical and catheter-based procedures in attempts to close a Swisscheese ventricular septum. The ultimate operation had entailed placing a large polytetrafluoroethylene (Gore-Tex, WL Gore and Associates, Flagstaff, AZ) patch across residual defects from the right ventricle (dotted lines in Figure 7). Because of the impenetrable nature of the right ventricular trabecular meshwork, the patch had created a large subcompartment within the right ventricle (asterisks in Figure 7). In addition, the shunt remained hemodynamically significant, with a ratio of pulmonary-to-systemic flows of 1.8 to 1 , with moderately elevated pressures in the apical component of the right ventricle. The model was used to evaluate possible options for effective surgical closure of the multiple septal defects (Figure 8). The most promising option for biventricular correction was deemed to be closure from a left ventriculotomy using a patch, concomitant with removal of the patch placed within the right ventricle.

\section{DISCUSSION}

Computerized 3D models of the heart provide comprehensive information about the intracardiac anatomy. Our experience has shown that the models 1) facilitate and improve 

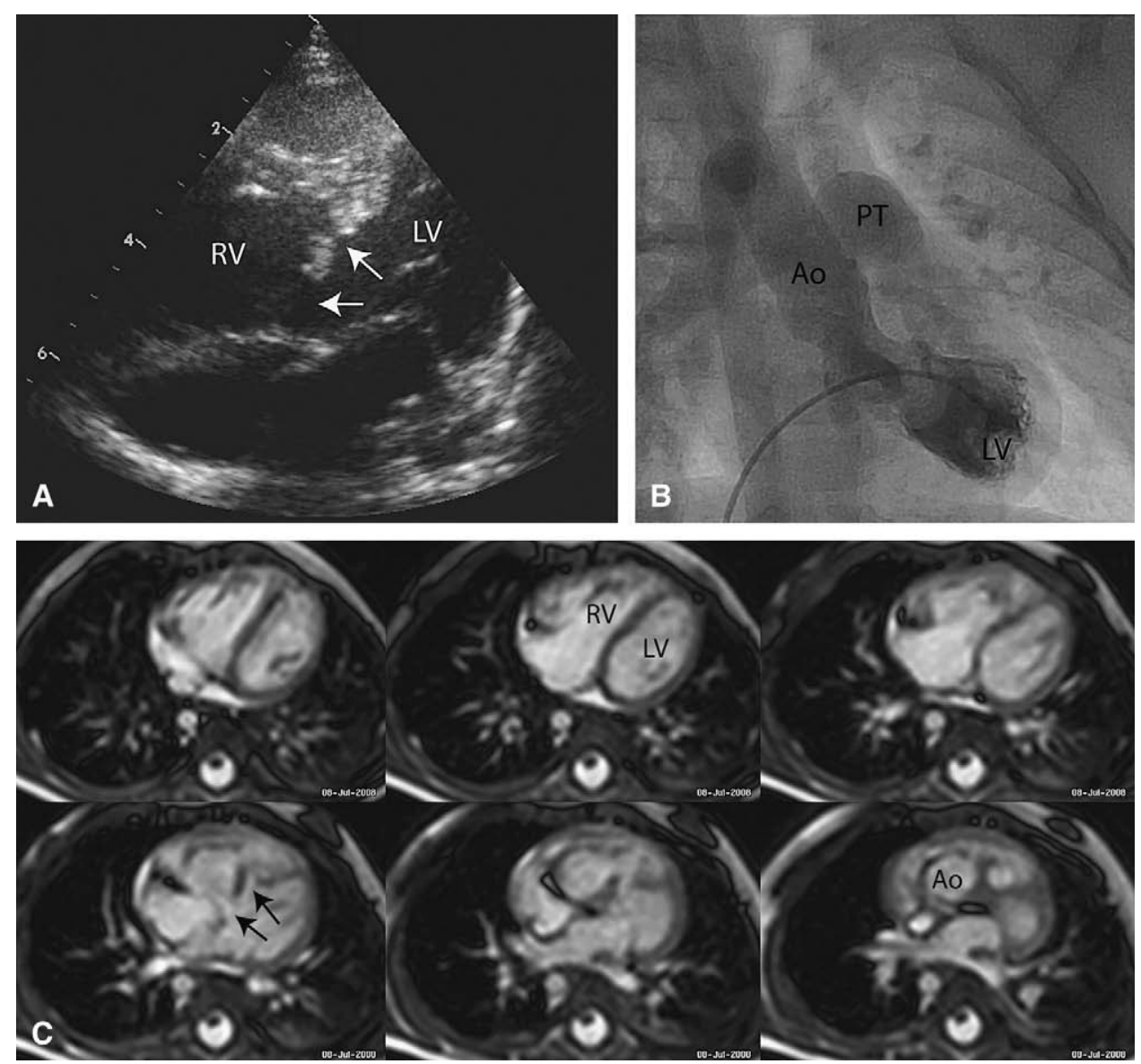

FIGURE 5. Standard diagnostic imaging of patient 2 with double-outlet right ventricle and multiple interventricular communications. Echocardiography (A, 4-chamber view), cardiac catheterization (B, anterior view of left ventricular angiography, catheter is placed into the left ventricle through the upper defect), and standard MRI (C, transversal cine MRI in end diastole) show multiple interventricular communications (arrows). The biventricular surgical approach could not be planned on the basis of these standard images. Ao, Ascending aorta; $L V$, left ventricle; $P T$, pulmonary trunk; $R V$, right ventricle.

the understanding of complex pathology and 2) provide decisive information about the spatial position, size, and relationship of distinctive structural anomalies.

Cardiovascular imaging in general has now evolved as an important and highly specialized field of medicine. To diagnose structural cardiac disease, clinicians now have access to several modalities, which include transthoracic and transesophageal echocardiography, MRI, CT, and x-ray angiography. Each of these methods has characteristic qualities, but also drawbacks, in terms of spatial and temporal resolution of the images provided, discrimination of soft tissues, or dependence on the operator. Despite enormous advances in
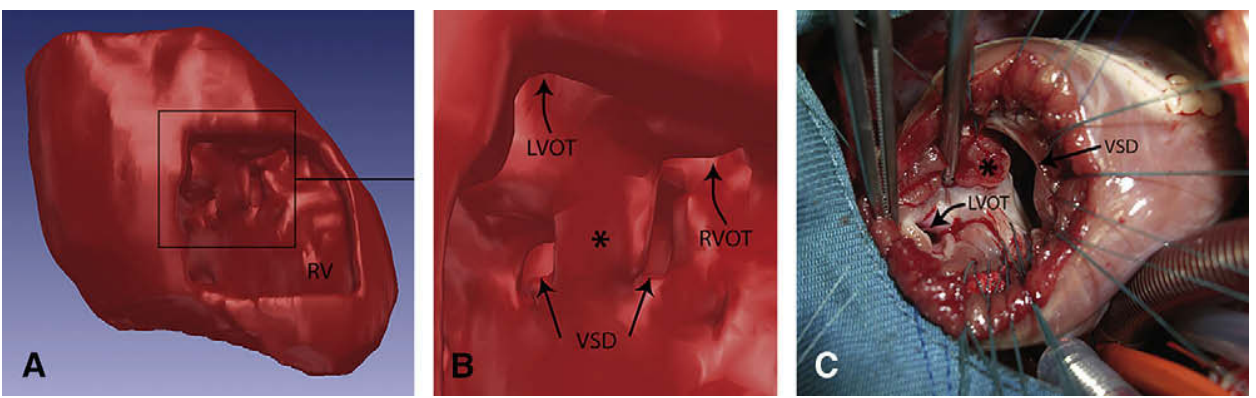

FIGURE 6. Virtual 3D surface model and intraoperative photograph of patient 2. Anterior view into the right ventricle in the virtual 3D surface model(A) with enlarged detail (B) shows the region of interest: the interventricular communication, divided by a muscle band (asterisk), in relation to the left ventricle and the origin of the outflow tracts from the right ventricle. Surgery included resection of the muscle band (asterisk, C, photographic image during operation with opened right ventricle). $L V O T$, Left ventricular outflow tract; $R V$, right ventricle; $R V O T$, right ventricular outflow tract; $V S D$, interventricular communication. 

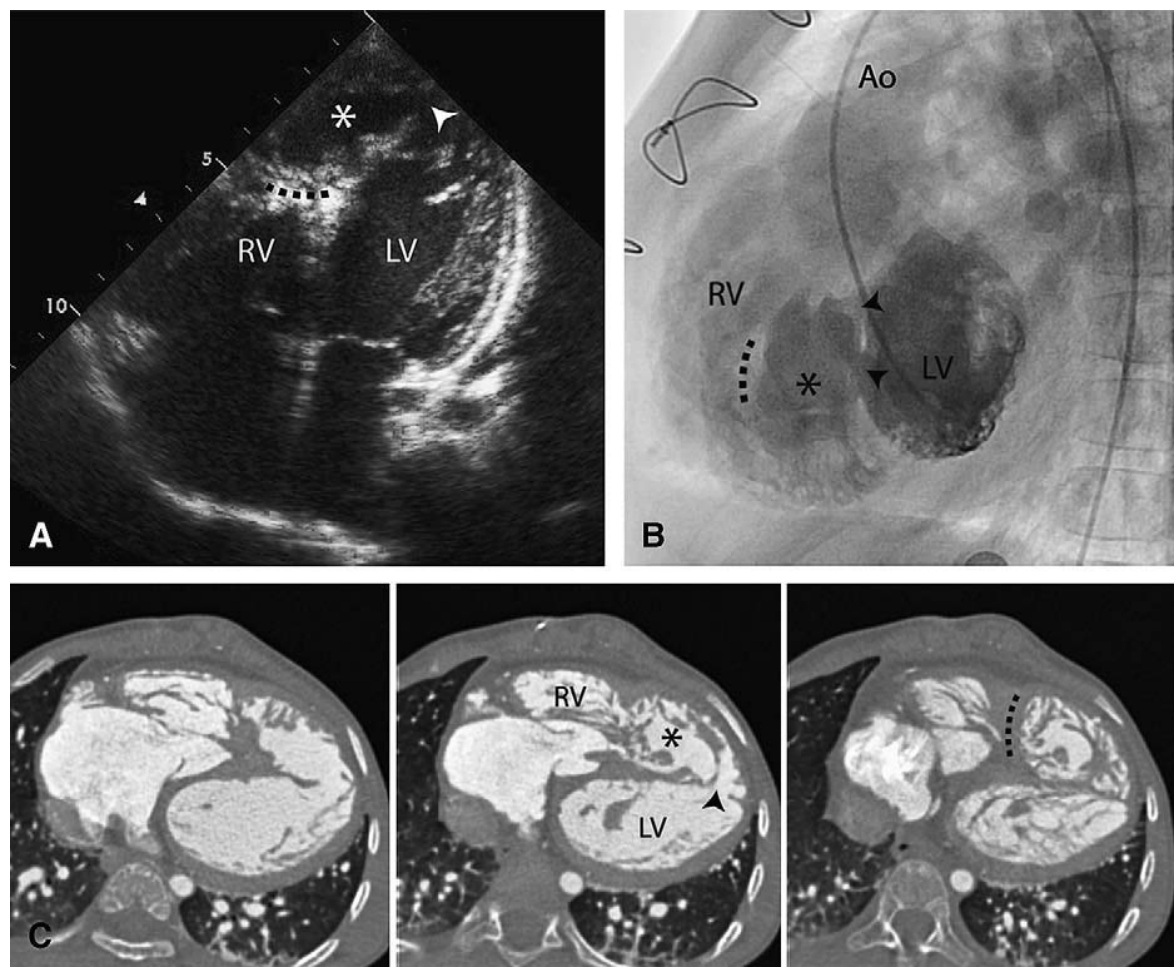

FIGURE 7. Standard diagnostic imaging of patient 3 with Swiss-cheese ventricular septum. Echocardiography (A, 4-chamber view), cardiac catheterization (B, lateral view of left ventricular angiography), and standard CT (C, transversal slices in end diastole) show the patch (dashed line) and subdivided right ventricle (asterisk), and residual defects (arrowheads). These standard imaging methods did not allow a unitary decision to be made on the surgical procedure for this patient. Ao, Ascending aorta; $L V$, left ventricle; $R V$, right ventricle.

technology, the clinical reality is that when interpreting demanding constellations of the anatomic structures, different observers may derive different interpretations when using conventional cardiac images. This is particularly problematic in the setting of complex congenital cardiac disease, when a lack of consensus between the responsible physicians may have an important impact on the management and outcomes for patients with such lesions.

Three-dimensional data sets can now be obtained when using all the modalities listed above. ${ }^{15-18}$ For extracardiac structures, such as the great arteries, data sets from magnetic resonance images, computed tomograms, or x-ray angiograms can all be reconstructed into true 3D images. Since their first development, such reconstructions have improved rapidly. Currently, they form part of the daily routine in cardiac imaging. In contrast, intracardiac anatomy of the entire heart based on 3D data sets obtained with echocardiography, MRI, or CT can be viewed only in multiplanar 2-dimensional planes. Although multiplanar viewing modes have been found to be helpful for assessment of anatomy, some variations may still arise in interpretations because perception of depth can vary substantially between different observers. ${ }^{19}$

Realistic 3D models of the heart were used in our study as an adjunct to images provided in conventional fashion for discussion of the potential surgical treatment of 11 preselected patients with complex congenitally malformed hearts. In these patients, conventional imaging had failed to reveal the relationships of all the anatomic features in an unequivocal manner. As a result, an unequivocal decision had not been reached on the optimum therapeutic strategies. We found that the models proved remarkably effective in demonstrating the complex anatomy, producing consensus in a more comprehensive and unmistakable manner, and permitted rapid conclusions concerning the surgical options. In addition, the availability of the printed physical models did not produce superior understanding when compared with the computerized analysis of the virtual models. We will be evaluating this issue in more systematic fashion as part of our future research, because printing the physical models becomes an important additional cost factor.

To reduce variability, advanced cardiovascular imaging demands techniques that are independent of the skills and experience of the operator. This requirement applies not only to the acquisition of images and post-processing for functional analysis but also to the assessment and interpretation of anatomy. In our study, the models were made from standardized scans that form part of our routine imaging and that are operator independent in terms of their acquisition. 

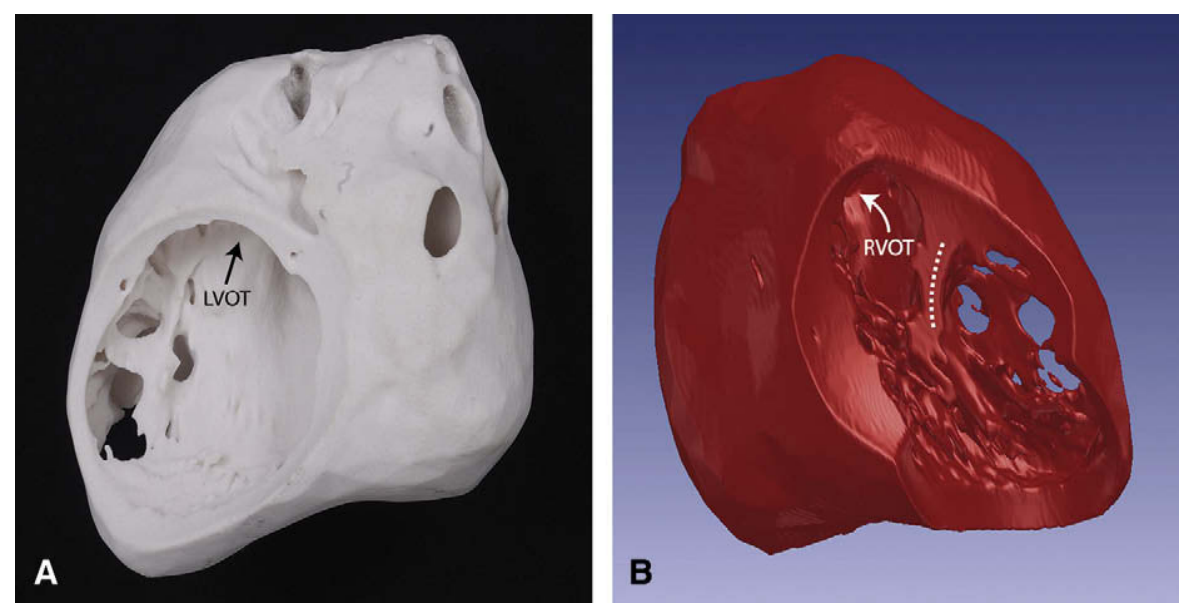

FIGURE 8. Printed and virtual 3D surface models of patient number 3. Posterior view to the left ventricle of the printed (A) and anterior view to the right ventricle of the virtual surface model (B). Residual ventricular septal defects are clearly seen, the dashed line indicates the patch, which divides the right ventricle. $L V O T$, Left ventricular outflow tract; RVOT, right ventricular outflow tract.

Spatial resolution of CT is superior when compared with MRI, but CT must be used with care because the method is known to be associated with considerable ionizing radiation, with its recognized carcinogenic effects and increased lifetime risk, especially in children. ${ }^{20,21}$ On the other hand, in small children with high heart rates, intracardiac anatomy is not necessarily better visualized by CT compared with MRI. ${ }^{22}$ Methods using cine MRI, as opposed to CT or whole-heart resonance imaging, also yield the advantage that quantitative function can be assessed in 1 step, together with anatomy. Unlike the techniques involving the whole heart, which are generally triggered in diastole, the cinebased models can be made at any arbitrary time point of the cardiac cycle. This issue might be important when visualizing dynamic changes in morphology.

\section{Study Limitations}

The 3D models of the heart suffer in that their clinical utility cannot be directly determined in quantitative fashion. There is no scaling of which we are aware that might measure the presumed improvements in diagnosis, surgical decision-making, surgical procedures performed, or even the outcome for patients. It is also scientifically inappropriate to postulate which therapeutic option might have been chosen without access to the models. We should also remember that some surgical options, for example, biventricular as opposed to functionally univentricular repair for some patients with double-outlet right ventricle, remain controversial. ${ }^{23}$ On the other hand, multiple operative procedures are often needed in the setting of complex anatomy, and optimal preoperative planning is therefore of the greatest clinical value. $^{24}$

The anatomy of the cardiac valvar leaflets was not integrated into the models because, as yet, their imaging remains difficult when using either MRI or CT. For certain anoma- lies, nonetheless, precise knowledge about cardiac valvar anatomy is invaluable. Future research must address this issue, which might be better accomplished by fusing the images obtained by the tomographic techniques with those now available echocardiographically.

\section{CONCLUSIONS}

Realistic 3D models of the heart provide detailed and comprehensive information on intracardiac anatomy. These models can be derived directly from standard tomographic imaging modalities and have been shown to have a significant impact on the diagnostic approach in patients with complex congenital cardiac lesions.

\section{References}

1. Minns RJ, Bibb R, Banks R, Sutton RA. The use of a reconstructed three-dimensional solid model from $\mathrm{CT}$ to aid the surgical management of a total knee arthroplasty: a case study. Med Eng Phys. 2003;25:523-6.

2. Winder J, Bibb R. Medical rapid prototyping technologies: state of the art and current limitations for application in oral and maxillofacial surgery. J Oral Maxillofac Surg. 2005;63:1006-15.

3. Mottl-Link S, Boettger T, Krueger JJ, Rietdorf U, Schnackenburg B, Ewert P, et al. Images in cardiovascular medicine. Cast of complex congenital heart malformation in a living patient. Circulation. 2005;112:e356-7.

4. Jacobs S, Grunert R, Mohr FW, Falk V. 3D-Imaging of cardiac structures using 3D heart models for planning in heart surgery: a preliminary study. Interact Cardiovasc Thorac Surg. 2008;7:6-9.

5. Kim MS, Hansgen AR, Wink O, Quaife RA, Carroll JD. Rapid prototyping: a new tool in understanding and treating structural heart disease. Circulation. 2008;117: 2388-94.

6. Mottl-Link S, Hubler M, Kuhne T, Rietdorf U, Krueger JJ, Schnackenburg B et al. Physical models aiding in complex congenital heart surgery. Ann Thorac Surg. 2008;86:273-7.

7. Ngan EM, Rebeyka IM, Ross DB, Hirji M, Wolfaardt JF, Seelaus R, et al. The rapid prototyping of anatomic models in pulmonary atresia. J Thorac Cardiovasc Surg. 2006;132:264-9.

8. Schievano S, Migliavacca F, Coats L, Khambadkone S, Carminati M, Wilson N, et al. Percutaneous pulmonary valve implantation based on rapid prototyping of right ventricular outflow tract and pulmonary trunk from MR data. Radiology. 2007;242:490-7. 
9. Sodian R, Schmauss D, Markert M, Weber S, Nikolaou K, Haeberle S, et al. Three-dimensional printing creates models for surgical planning of aortic valve replacement after previous coronary bypass grafting. Ann Thorac Surg. 2008; 85:2105-8.

10. Sodian R, Weber S, Markert M, Loeff M, Lueth T, Weis FC, et al. Pediatric cardiac transplantation: three-dimensional printing of anatomic models for surgical planning of heart transplantation in patients with univentricular heart. $J$ Thorac Cardiovasc Surg. 2008;136:1098-9.

11. Sodian R, Weber S, Markert M, Rassoulian D, Kaczmarek I, Lueth TC, et al. Stereolithographic models for surgical planning in congenital heart surgery. Ann Thorac Surg. 2007;83:1854-7.

12. Sorensen TS, Beerbaum P, Mosegaard J, Rasmusson A, Schaeffter T, Austin C, et al. Virtual cardiotomy based on 3-D MRI for preoperative planning in congenital heart disease. Pediatr Radiol. 2008;38:1314-22.

13. Wolf I, Vetter M, Wegner I, Bottger T, Nolden M, Schobinger M, et al. The medical imaging interaction toolkit. Med Image Anal. 2005;9:594-604.

14. Bottger T, Kunert T, Meinzer HP, Wolf I. Application of a new segmentation tool based on interactive simplex meshes to cardiac images and pulmonary MRI data. Acad Radiol. 2007;14:319-29.

15. Bailliard F, Hughes ML, Taylor AM. Introduction to cardiac imaging in infants and children: techniques, potential, and role in the imaging work-up of various cardiac malformations and other pediatric heart conditions. Eur J Radiol. 2008; 68:191-8. Epub 2008 Sep 4.
16. Bharucha T, Roman KS, Anderson RH, Vettukattil JJ. Impact of multiplanar review of three-dimensional echocardiographic data on management of congenital heart disease. Ann Thorac Surg. 2008;86:875-81.

17. Ou P, Celermajer DS, Calcagni G, Brunelle F, Bonnet D, Sidi D. Three-dimensional CT scanning: a new diagnostic modality in congenital heart disease. Heart. 2007;93:908-13.

18. Rigatelli G, Zamboni A, Cardaioli P, Scaranello F, Giordan M, Dell'Avvocata F, et al. Three-dimensional rotational digital angiography in catheter-based congenital heart disease interventions. J Cardiovasc Med (Hagerstown). 2008;9:432.

19. Bulthoff I, Bulthoff H, Sinha P. Top-down influences on stereoscopic depthperception. Nat Neurosci. 1998;1:254-7.

20. Brody AS, Frush DP, Huda W, Brent RL. Radiation risk to children from computed tomography. Pediatrics. 2007;120:677-82.

21. Kleinerman RA. Cancer risks following diagnostic and therapeutic radiation exposure in children. Pediatr Radiol. 2006;36:121-5.

22. Taylor AM. Cardiac imaging: MR or CT? Which to use when. Pediatr Radiol. 2008;38(Suppl 3):S433-8.

23. Delius RE, Rademecker MA, de Leval MR, Elliott MJ, Stark J. Is a high-risk biventricular repair always preferable to conversion to a single ventricle repair? J Thorac Cardiovasc Surg. 1996;112:1561-9.

24. Bradley TJ, Karamlou T, Kulik A, Mitrovic B, Vigneswaran T, Jaffer S, et al. Determinants of repair type, reintervention, and mortality in 393 children with double-outlet right ventricle. J Thorac Cardiovasc Surg. 2007;134:967-73, e966. 